\title{
Seasonal Variation in the Prevalence of Post-abortion Complication in Northern Nigeria
}

\author{
Article by Mathew Okoh \\ Johns Hopkins Center for Communications Program \\ E-mail:mathewokoh@yahoo.com
}

\begin{abstract}
Complications from miscarriages and unsafe abortion often lead to short and long term morbidities. About $40 \%$ of maternal deaths in Nigeria are attributable to complications from miscarriage and unsafe abortion. Seasonal variations in the incidence and prevalence of spontaneous miscarriage have been reported in other climes but there is no literature describing this phenomenon in Nigeria.

This analysis aimed to determine if there was a seasonal variation in the prevalence of post abortion complications cases managed in Kano State, Nigeria.

This analysis was based on a retrospective review of records of all women who presented for treatment of post abortion complications in 30 hospitals over a 36 months period. Stata SE version 14 was used for analysis.

Aggregated monthly number of cases over the three year period revealed a cyclical pattern with two dips in December and June and a peak around the months of February and March. This pattern remained consistent when the data was disaggregated into the different years. No statistically significant difference was observed in the number of PAC cases treated during the rainy season compared to those treated in the dry season. However, there was a statistically significant difference in the number of PAC cases treated in the first year compared to the second and third year.

Findings from this study indicates that there was no difference in the number of PAC cases treated in Kano state during the rainy season compared to those treated during the dry season. The number of cases treated however, appeared to differ across years.
\end{abstract}

Keywords: Miscarriage, Complication, Post-abortion care, Post-abortion contraception, seasonal, Trimester.

\section{Introduction}

Post-abortion complication is the term used to describe the after effect of incomplete spontaneous abortion (miscarriage) or an unsafe abortion. Miscarriage is loss of pregnancy before 20 weeks gestation usually without any deliberate external intervention. Unsafe abortion on the other hand, is defined by the World Health Organization (WHO) as a procedure for terminating an unintended pregnancy, carried out either by persons lacking the necessary skills or in an environment that does not conform to minimal medical standards, or both (WHO (2012). Post-abortion complication whether from a miscarriage or unsafe abortion, is often associated with one or more of the following; retained product of conception, bleeding, and infection. Post-abortion complications are estimated to contribute up to $40 \%$ of maternal deaths in Nigeria (Oye-Adeniran, Umoh, \& Nnatu, 2002; Omo-Aghoja, Aisien, Akuse, Bergstrom, \& Okonofua, 2010). In addition, it also leads to short and long term disabilities (WHO, 2012; AbouZahr, 2003) including chronic pain, pelvic inflammatory disease, tubal occlusion and secondary infertility (Corbett, \& Turner, 2003). If not properly treated. In 2006, it was reported that 760,000 abortion procedures were performed in Nigeria, most of which were unsafe (Sedgh et al, 2006). It is also estimated that $20 \%$ of all pregnancies end in spontaneous miscarriages (Griebel, Halvorsen, Golemon, \& Day, 2005). All these underscores the burden of abortion related complications and the importance of the availability and access to high quality post-abortion care services in Nigeria.

Post-abortion care (PAC) is the procedure for treating or managing complication from incomplete miscarriage and unsafe abortions by removing the remaining products of conception from the uterus and treating associated complications. Post abortion care is a continuum of treatment that includes 
counselling and provision of post abortion contraception as well as referral for other reproductive health services (Ipas, 1991). The essential elements of post abortion care are illustrated below.

\section{Essential Elements of Post abortion Care}

\section{Community and service provider partnerships}

- Prevent unwanted pregnancies and unsafe abortion

- Mobilize resources to help women receive appropriate and timely care for complications of abortion

- Ensure that health services reflect and meet community expectations and needs

\section{Counselling}

- Identify and respond to women's emotional and physical health needs and other concerns Treatment

- Treat incomplete and unsafe abortion and potentially life-threatening complications

Family planning and contraceptive services

- Help women practice birth spacing or prevent an unwanted pregnancy

Reproductive and other health services

- Preferably provide on-site, or via referrals to other accessible facilities in provider's network

Source: Post abortion Care Consortium Community Task Force, Essential Elements of Post abortion Care: an expanded and updated model, PAC in Action, 2002, No. 2, Special Supplement.

Environmental factors and weather conditions have been documented to have negative effect on human health. For example, air pollution has been linked to respiratory and cardiopulmonary diseases as well as reduced life expectancy by several authors (Pope, Ezzati, \& Dockery, 2009; Cohen, 2000; Vineis, Forastiere, Hoek, \& Lipsett, 2004; Brunekreef, 2007). Similarly, variations in the weather condition can also negatively impact different aspect of human health including reproductive health. Temperature, humidity and sunlight have all been shown to be associated with poor birth outcomes (Basu, Malig, \& Ostro, 2010; Elter, AY, Uyar, \& Kavak, 2004; Murray et al, 2000; Tustin, Gross, \& Hayne, 2004; Yackerson, Piura, \& Sheiner, 2008; Flouris, Spiropoulos, Sakellariou, \& Koutedakis, 2009; McGrath, Barnett, \& Eyles, 2005). Furthermore, Chodick et al (2009), Strand et al (2011) and Lee et al (2006) have independently demonstrated that birth outcomes are related to the season in which they occur and that these seasonal effects vary between populations and geographic location. For example, exposing pregnant women to extreme heat have been shown to be associated with low birth weight (Deschenes, Greenstone, \& Guryan, 2009). While increased humidity have also been linked to preeclampsia and eclampsia (Subramanjam, 2007).

In addition to the health effects and poor pregnancy outcomes mentioned above, seasonal changes have also been shown to be associated with spontaneous abortion since the early seventies when McDonald documented an excess of abortion during the spring months using data collected from seven hospitals in Montreal, Canada. He further explained that this finding could be due to the prevalence of infective agents during spring (McDonald, 1971). Similarly, a population based survey of women who experienced spontaneous loss of pregnancies over a period of 10 years (1971-1980) in Hungary, indicated that the prevalence was highest during the months of October to February (Czeizel, Bognar, $\&$ Rockenbauer, 1984). Weinberg and colleagues prospectively followed 221 women who were actively trying to get pregnant in the United States over a period of 3 years. Findings from this study indicated that the risk of spontaneous abortion was highest in the months of September to December of each of the 3 years (Weinberg, Moledor, Baird, \& Wilcox, 1994). There appears to be an abundance of literature concerning the effects of seasonality on other pregnancy outcomes but not that much literature with specific reference to spontaneous abortion is available. The few studies with specific focus on abortion were all conducted in developed countries like the United States and in European countries.

There is no evidence that there has been any study to investigate the role of seasonality in the prevalence of spontaneous abortion in Africa as a whole and Nigeria in particular. Examining the occurrences of poor pregnancy outcomes and seasonality could help us to understand the risk factors 
associated with them and ultimately identify the causal links. Furthermore, understanding these seasonal variations could help inform the design and implementation of intervention measures to mitigate the effects of seasonality or improve pregnancy outcomes during these seasons. This study is therefore intended to investigate if there is any seasonal variation in the prevalence of post abortion complication resulting from miscarriages in Kano State Nigeria. Kano State was chosen because it represents northern Nigeria. Northern civilization and Islamization of the north began from Kano State which also became the first administrative headquarters of northern Nigeria. This study could provide valuable information that might be needed to improve the availability and quality of post abortion care services provided in Kano State hospitals.

The broad objective of the study was to determine if there was a seasonal variation in the prevalence of post abortion complications in Kano State.

- To determine if there was a difference in the number of women presenting for post abortion care services between the rainy and dry season.

- To determine if the was a difference in the number of women presenting for post-abortion care services between the four quarters of the year.

\section{Methodology}

\section{Background of study area}

Kano is one of the 36 States in Nigeria and was created on the $27^{\text {th }}$ of May 1967 from the Northern region. Kano State has 44 Local Government Areas (LGA) and lies in North Western Nigeria between latitudes $11^{\circ} 30^{\prime} \mathrm{N}$ and longitude $8^{\circ} 30^{\prime} \mathrm{E}$. It is bordered by Katsina State to the North-West, Jigawa State to the North-East, Bauchi State to the South-East and Kaduna to the South-West. Kano State has a land mass of 20,680 square kilometers with a population of 9,383,682 making it the most populous State in Nigeria according to the 2006 census. The main inhabitant of Kano are the Hausa people and the Hausa language is widely spoken in Kano like in other parts of Northern Nigeria. Fulani is also a common language spoken in Kano state. Islam is the predominant religion practiced in Kano State, a small minority of the population practice Christianity and other non-Muslim religion.

The people of Kano State engage in commercial, industrial and agricultural activities. Subsistence and commercial farming are practiced in Kano State while the commercial and industrial activities include: textile, tanning, footwear, cosmetics, plastics, enamelware, pharmaceuticals, ceramics, furniture and other industries. Agricultural produce include: millet, cowpeas, sorghum, maize, rice which are grown for local consumption with women playing significant roles. Groundnuts which used to be a major source of revenue for Nigeria and cotton are produced for export and industrial purposes.

Kano State like other parts of Nigeria experiences a rainy season (April to September) and a dry season (October to March). Kano State gets around $690 \mathrm{~mm}$ of rain fall per year, with much of that occurring from June through September. Kano has a tropical climate with rainy and dry seasons influenced by the rain-bearing South-westerly winds and the cold, dry, and dusty north-easterly winds, commonly referred to as the Harmattan (mostly in December and January).

\section{Study type}

This was a retrospective review of hospital records of women who presented at the hospitals for treatment of post abortion complications (PAC) between October 2011 and September 2014. This approach was easier, less time consuming and cheaper than collecting the data prospectively. Data for this study were retrieved from the records of 30 hospitals participating in a post abortion care intervention in Kano State Nigeria. Ninety three percent (28) of the hospitals were secondary level hospitals and $90 \%$ were public sector hospitals.

\section{Study population}

All women who were documented in hospital records as having received treatment for post abortion complications during the period under review were included for analysis. 
DOI: $10.21522 /$ TIJPH.2013.05.04.Art016

ISSN: $2520-3134$

\section{Data collection and analysis}

Each hospital maintains a register (logbook) that is used to keep record of all uterine evacuation services provided. Fourteen thousand and seventeen women were documented as having received a post abortion care procedure during this period under review. Duplicate copies of logbook pages with deidentified records of women treated for post-abortion complications were obtained and entered into excel and finally converted to a Stata dataset. Data were analysed using Stata version 14. Chi-square, student t-test and Kruskal Wallis tests were used to examine association and differences in mean between variables of interest.

\section{Ethical considerations}

Each hospital gave permission for de-identified data to be retrieved from the hospital records.

\section{Results}

\section{Demographics}

A total of 14,017 women were documented to have received post abortion care. Mean age was 26 years (SD 6.5). Mean gestational age at the time post abortion complication was experienced was 10 weeks and most (99\%) of the procedures were performed using World Health Organization approved methods of vacuum aspiration and misoprostol (see table 1). A little more than half (59\%) of the women accepted a contraceptive method following their care and $95 \%$ of them received medications to help relieve pain during the procedures.

Table 1. Descriptive characteristics of women who received PAC services

\begin{tabular}{|l|l|l|}
\hline Variable & Subcategory & $\mathbf{n}(\%)$ \\
\hline Age of women $(\mathrm{n}=14,017)$ & Less than 20 years & $1,741(12 \%)$ \\
& 20 to 24 years & $3,856(28 \%)$ \\
& 25 years and older & $7,793(56 \%)$ \\
& Age missing & $627(4 \%)$ \\
\hline Gestation at time of experiencing & Less than 13 weeks & $12,676(90 \%)$ \\
complication & 13 to 26 weeks & $996(7 \%)$ \\
& Gestation missing & $345(3 \%)$ \\
\hline Procedure method used to provide & EVA/MVA/Misoprostol & $13,916(99 \%)$ \\
post abortion care & Other methods & $101(1 \%)$ \\
\hline Uptake of a contraceptive method & Yes & $8,270(59 \%)$ \\
& No & $5,747(41 \%)$ \\
\hline & & \\
\hline
\end{tabular}

\section{Women who received post abortion care by year and season}

Data collected for this study spanned a period of three years from October 2011 to September 2014. October 2011 to September 2012 represents the first year, while October 2012 to September 2013 represents year 2 and October 2013 to September 2014 represents the third year. The number of women treated in each year is represented in figures 1 and 2. 


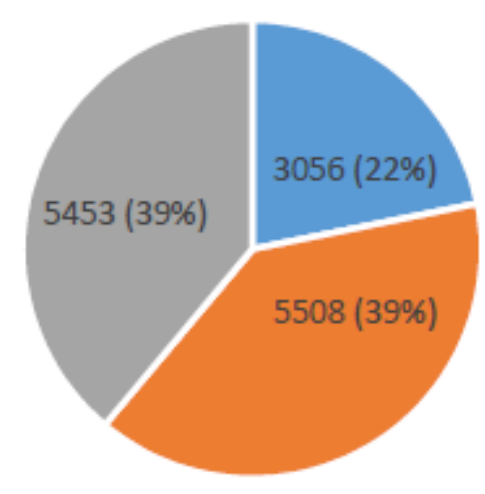

- October 2011 to September 2012 - October 2012 to September 2013

= October 2013 to September 2014

Figure 1. Women who received PAC

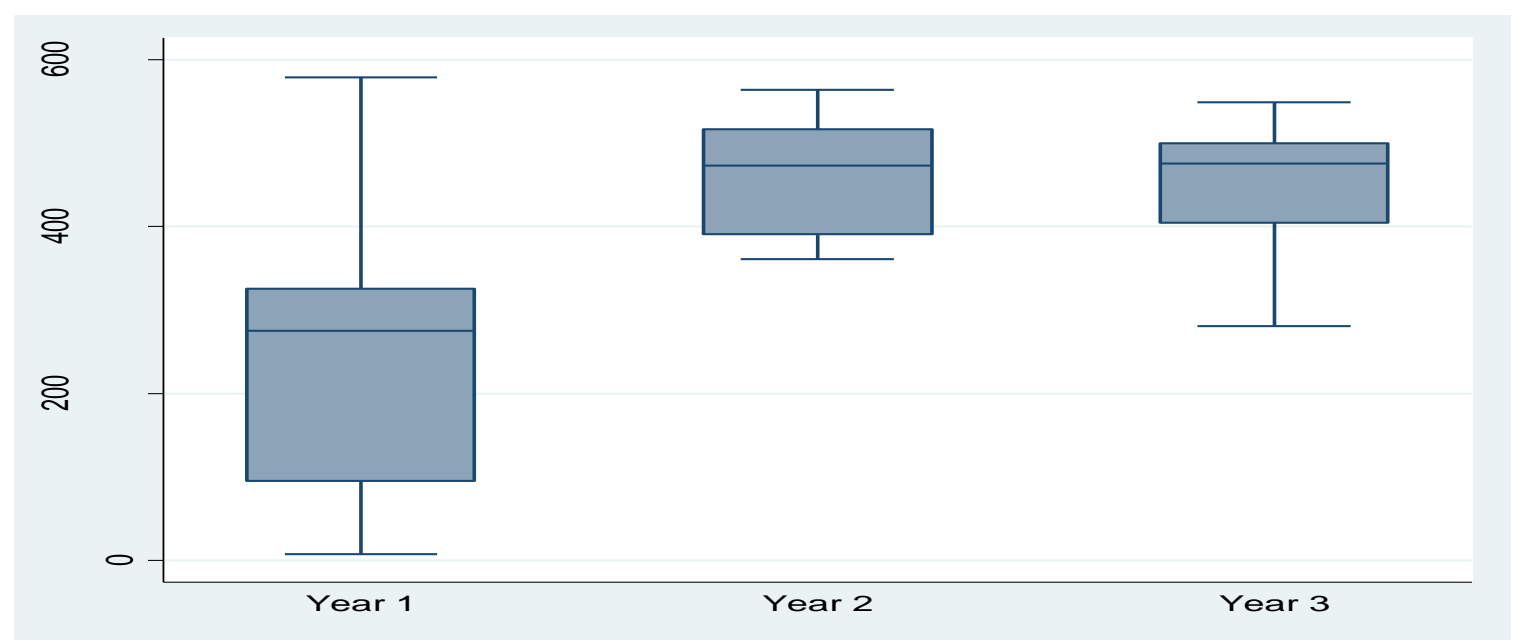

Figure 2. Box plot of women treated for post-abortion complication by year

The data indicated that the number of women treated for PAC increased from the first to the second year but dropped slightly in the third year. However, most $(78 \%)$ of the women were treated in the second and third year with only 55 women as difference between them. When the data was disaggregated by year and season, the number of women treated during the rainy season in the first two years were more than those treated in the dry season. This was however different in the third year where the number of women treated in the dry season was more than those treated in the rainy season as shown in figure 3 below. Student $t$ test was used to examine for differences in the means of women who received post abortion care between the dry and rainy season. Overall, there was no difference between the number of women treated between the dry and rainy season with a result of $t=0.6156$ and a $p$-value of 0.5433 ( 2 tailed). When the means of women treated during the dry and rainy season were compared for each of the three years, only the second year (October 2012 to September 2013) returned a statistically significant result indicting that more women were treated during the rainy season compared to dry season in the second year $(\mathrm{t}=2.2474$, $\mathrm{p}$-value $=0.0247)$. 
DOI: $10.21522 / \mathrm{TIJPH} .2013 .05 .04 . A r t 016$

ISSN: $2520-3134$

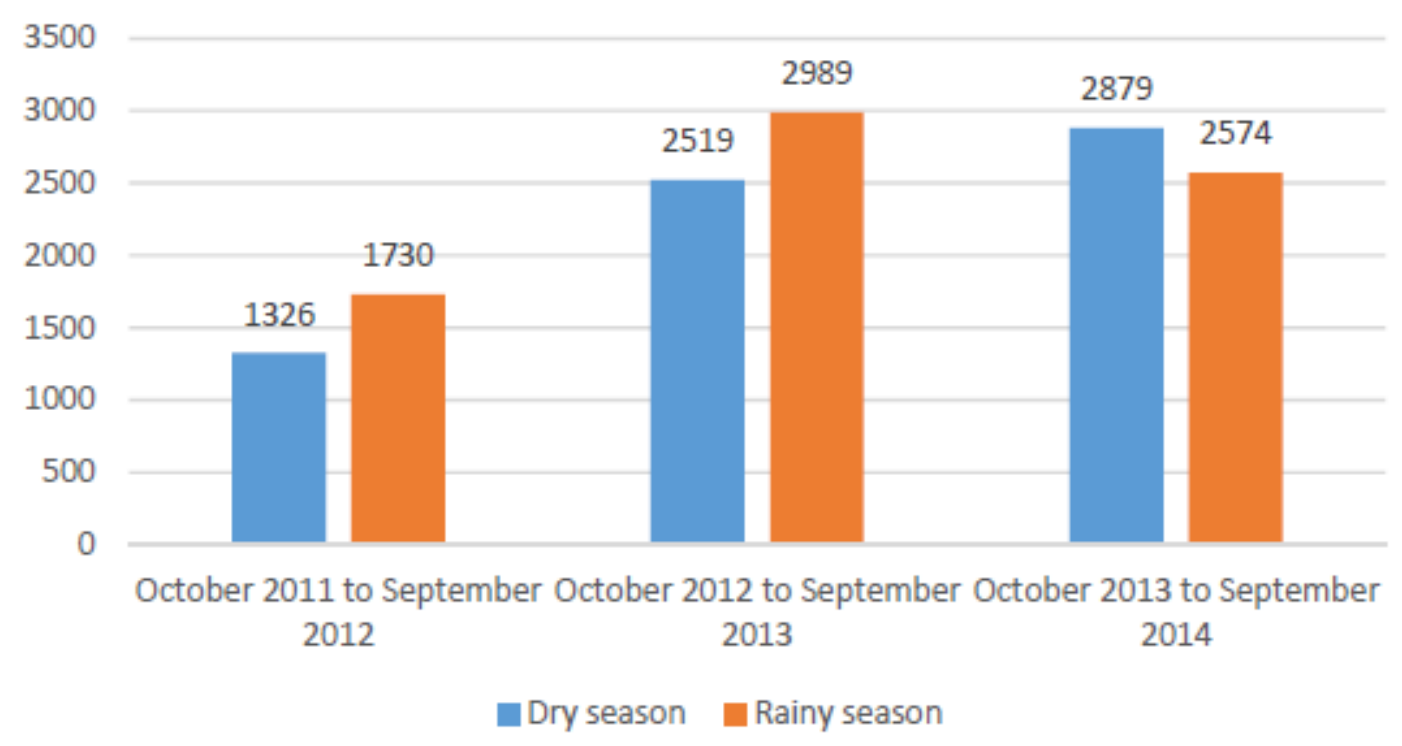

Figure 3. Women treated by year and season

\section{Number of women who received post abortion care in each quarter of the year}

When the number of women treated was disaggregated into 3 monthly period as shown in figures 4 and 5, no consistent pattern was observed in the data trends over time. Furthermore, a Kruskal Wallis $\mathrm{H}$ test did not show any statistically significant difference between periods $X^{2}(3)=3.039, p=0.3857$. A box plot revealed wide spread in data reported across the different periods as shown in figure 5 .

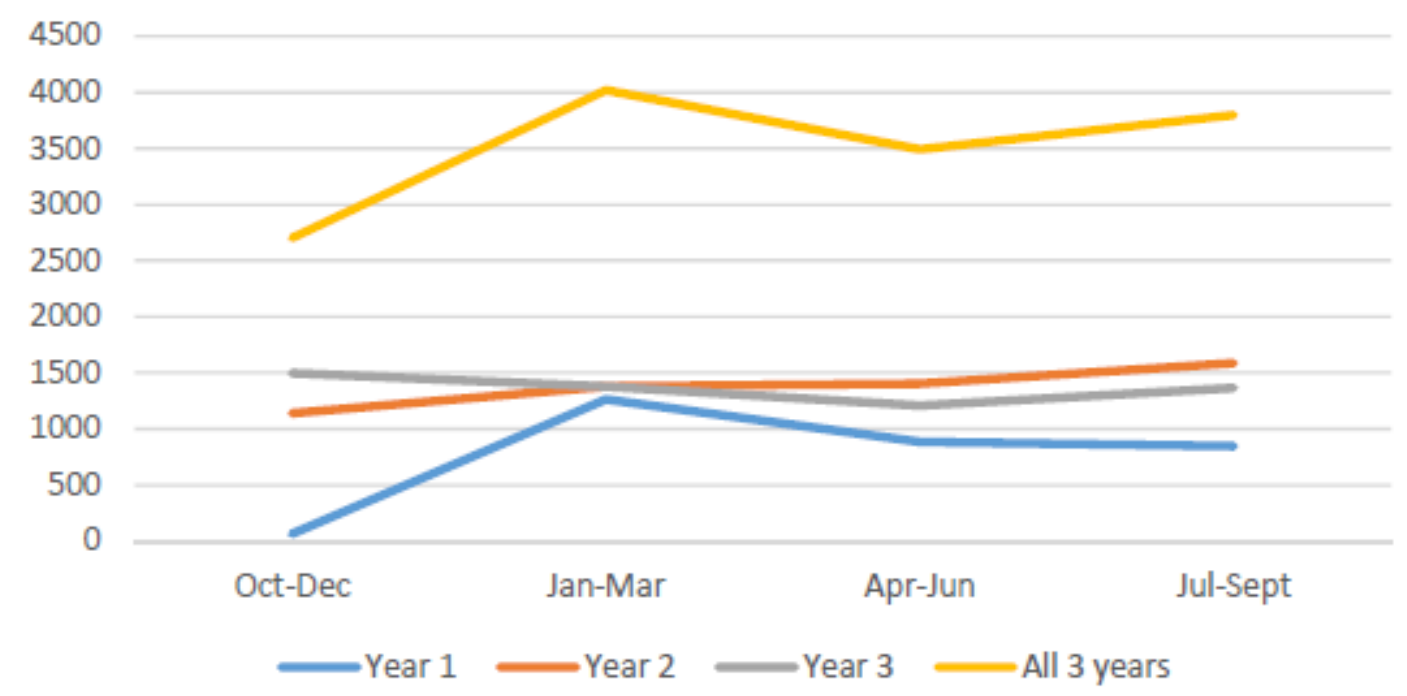

Figure 4. Number of women treated for post-abortion complication by periods of the year 


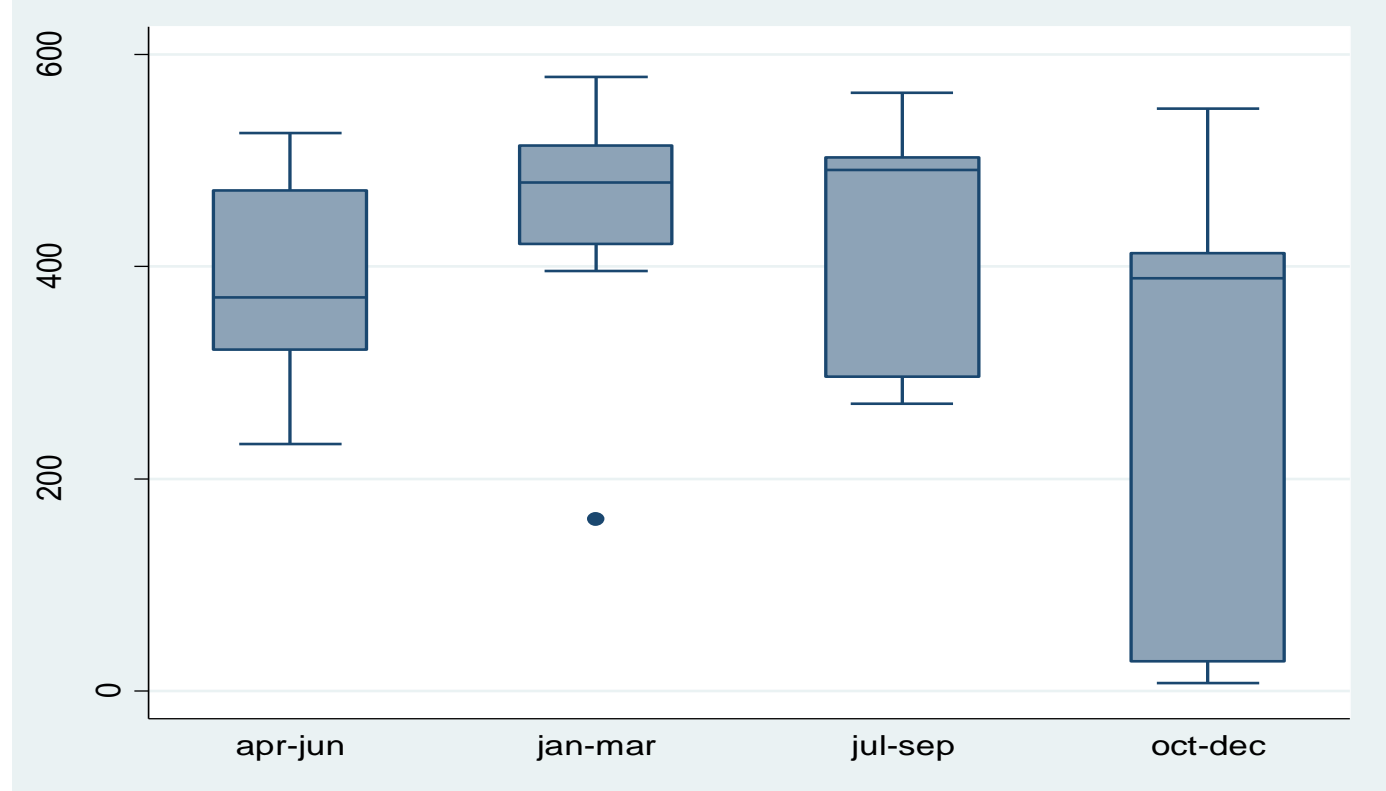

Figure 5. Number of women treated in each 3 month period of the year

\section{Women who received post abortion care in each month}

A review of the aggregated number of cases by month over the three year period revealed a cyclical pattern with two dips in December and June and a peak around the months of February and March. This pattern was also found to be consistent when the data was broken down into the three different periods (see figures 6 and 7).

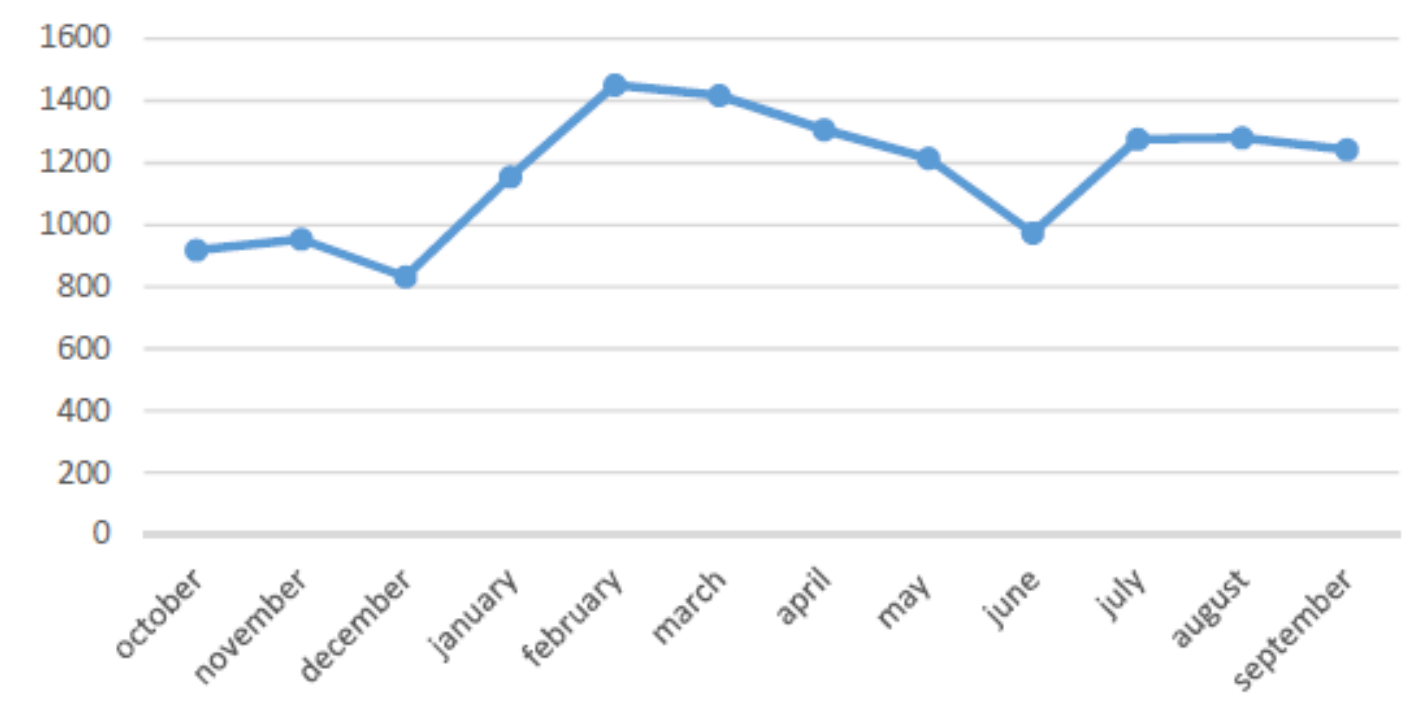

Figure 6. Cumulative number of cases for each over the three year period 
DOI: $10.21522 / \mathrm{TIJPH} .2013 .05 .04$.Art016

ISSN: $2520-3134$

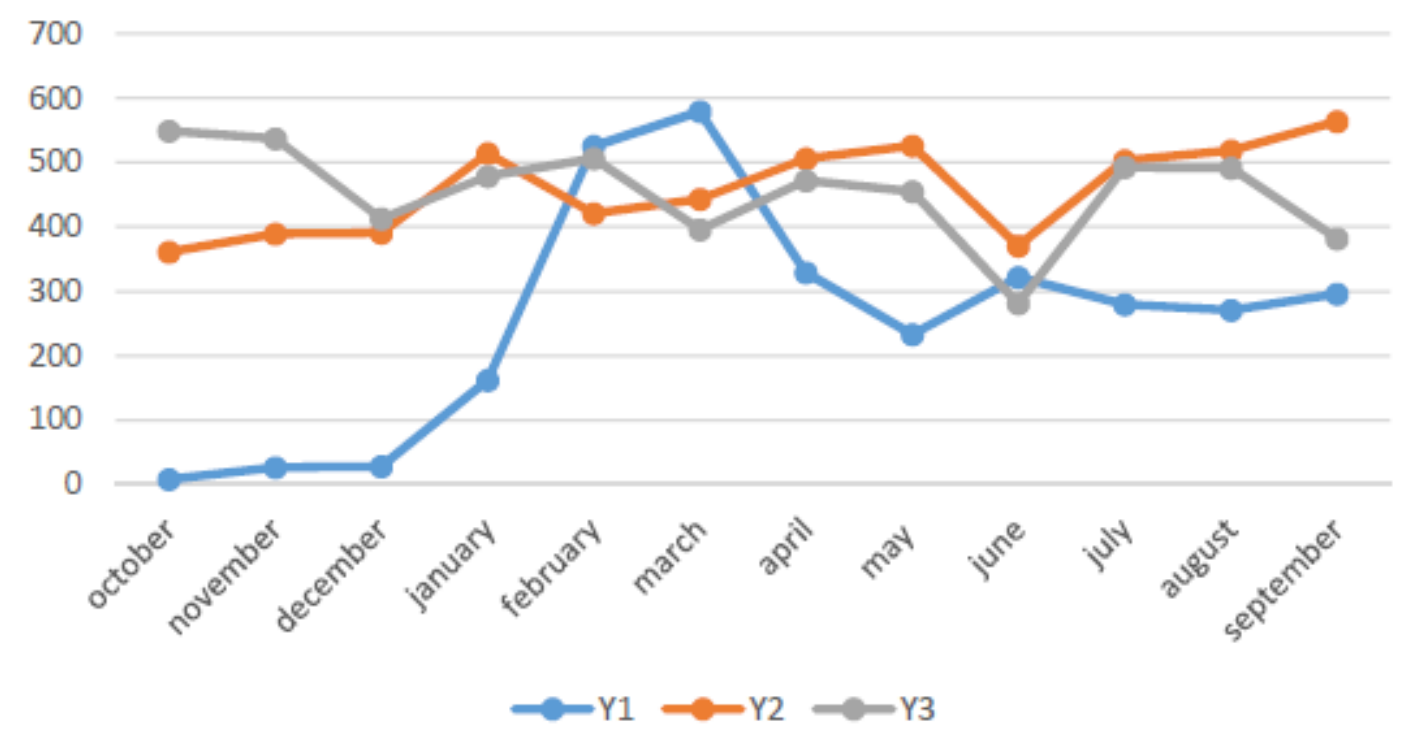

Figure 7. Number of cases by month in each of the three years

\section{Discussion}

The women represented in this data were generally young. More than three-quarters of the women treated for post abortion complications in the period under review were 30 years old or younger. This is not surprising giving the early age of marriage in northern Nigeria including Kano State from where this data was collected. However, data on marital status was not available for review.

Nine in ten of the women experienced complication and presented for treatment during the first trimester of their pregnancy. This again, is not strange since most cases of miscarriage and its complication usually occur in the first twelve weeks of pregnancy (Czeizel, Bognar, Rockenbauer, 1984). The preponderance of use of manual/electric vacuum aspiration and misoprostol is an indication that women who present for post abortion care services are treated with appropriate technology as recommends by the world health organization (WHO, 2012).

The data for the period under review exhibited a cyclical pattern in the number of post abortion care cases seen. Thus indicating that more cases are seen at certain months of the year than in other months. However, when data was grouped into rainy and dry season as well as different quarters of the year, no consistent pattern was observed. There was a statistically significant difference in the mean number of women who received post abortion care during the rainy season compared to the dry season in the period between October 2012 and September 2013 (year 2). This however, was not the case for the period between October 2011 to September 2012 (year 1) and October 2013 to September 2014 (year 3 ). This inconsistency would suggest that there is no seasonal variation (dry vs rainy season) in the number of women treated for post abortion complications in Kano State. This finding would suggest that there are other factors that vary from month to month that could be responsible for the cyclical pattern of the data observed, the effects of which when grouped together nullify each other.

The seasons investigated here, were comprised of six months period (October to March $=$ dry season and April to September = rainy season) which is twice that in order studies that found seasonal variation in the prevalence of spontaneous abortion. Most of these studies were in countries where the season is divided into four (winter, spring, summer and autumn) and each of them has only three months. This difference in time period may have accounted for why there appears not to be a significant difference between the two seasons examined in this study (McDonald, 1971; Czeizel, Bognar, \& Rockenbauer 1984; Weinberg, Moledor, Baird, \& Wilcox, 1994; Enkhmaa, 2014; George, Granath, Johansson, Annerén, \& Cnattingius, 2006). A disaggregation of the data into four periods of three monthly interval also did not show a significant variation in the outcome variable. Furthermore, the occurrence of spontaneous abortion could be due to unknown environmental factors that fluctuates with season in these industrialized nation that are not present in Kano state where this data was collected. However, giving the increase in farming activities and role of women in farming activities in Kano as well as the 
potential for increased malaria incidence associated with the rainy season, one would have expected to see a significant difference in the mean number of women treated for post abortion complication during the rainy season compared to the dry season. There is therefore a need for further research in this area in order to conclusive determine if there is any relationship between the prevalence of miscarriage and certain times of the year in Kano state and the environmental factors associated with those risks.

Contraceptive uptake was higher in this group of women compared to the general population (NPC \& ICF International, 2014). The injectable method was the most commonly accepted method among this population (data not shown). This could be a reflection of the conservative nature of this Muslim dominated setting. The use of contraceptive methods is generally frowned at in northern Nigeria. So, the uptake of injectable methods could be a way of minimizing the risk of being identified as a contraceptive user. According to the NDHS 2013 injectable contraceptive methods are the most commonly used methods by women in the north (NPC \& ICF International, 2014).

\section{Strengths and limitations}

The strength of this study include a large sample size and a relatively long time span of 36 months. This analysis was limited by several factors. Firstly, data was clinic based and could have excluded some women who may have had need for post abortion care services in the period under review but did not present at hospital. Although McDonald also used hospital records for his study and noted significant seasonal variation (McDonald, 1971). This unaccounted for women could have influenced the data in ways that cannot be explained. Similarly, it is possible that health care providers may not have documented all women who presented at the hospitals for post abortion care. This undocumented women could also have influenced this results in a different way. Thirdly, the incomplete nature of the data available especially as it concerns the demographic characteristics of the women e.g. educational status, marital status, parity among others limited the ability to explore the data in detail. There could have been misclassification of diagnosis as women who may have initiated their process of abortion could have presented as women experiencing spontaneous abortion.

\section{Conclusion and recommendation}

Overall more women sought for and received post abortion care in Kano during the rainy season than in the dry. However, results from statistical test were inconsistent overall and across years. Despite the inconsistency in statistical tests, there is need to plan for adequate resources both human and material in order to efficiently attend to the number of women seeking post abortion care in Kano State hospitals irrespective of the season.

There is need for further research to conclusively establish if there is any seasonal variation in the number of women treated for post abortion complication in kano State.

\section{References}

[1]. AbouZahr C. (2003). Global burden of maternal death and disability. Br Med Bull.; 67:1-11.

[2]. Basu R, Malig B, Ostro B. (2010). High ambient temperature and the risk of preterm delivery. Am J Epidemiol. 172:1108-1117.

[3]. Brunekreef B. (2007). Health effects of air pollution observed in cohort studies in Europe. J Expo Sci Environ Epidemiol. 17 Suppl; 2:S61-S65.

[4]. Chodick G, Flash S, Deoitch Y, Shalev V. (2009). Seasonality in birth weight: review of global patterns and potential causes. Hum Biol. 81:463-477.

[5]. Cohen A.J. (2000). Outdoor air pollution and lung cancer. Environ Health Perspect, 108 Suppl; 4:743-750.

[6]. Corbett MR, Turner KL. (2003). Essential Elements of Postabortion Care: Origins, Evolution and Future Directions. Int Fam Plan Perspect. 29(3):106-111.

[7]. Czeizel A, Bognar Z, Rockenbauer M. (1984). Some epidemiological data on spontaneous abortion in Hungary, 1971-1980. J Epidemiol Community Health. 38:143-148.

[8]. Deschenes O, Greenstone M, Guryan J. (2009). Climate Change and Birth Weight. American Economic Review. 99(2):211-17.

[9]. Elter K, AY E, Uyar E, Kavak ZN. (2004). Exposure to low outdoor temperature in the midtrimester is associated with low birth weight. Aust New Zeal J Obstet Gynaecol. 44:553-557. 
DOI: $10.21522 /$ TIJPH.2013.05.04.Art016

ISSN: 2520-3134

[10]. Enkhmaa D, Warburton N, Javzandulam B, Uyanga J, Khishigsuren Y, Lodoysamba S, et al. (2014). Seasonal ambient air pollution correlates strongly with spontaneous abortion in Mongolia. BMC Pregnancy and Childbirth. 14:146 available from http://www.biomedcentral.com/1471-2393/14/146

[11]. Flouris AD, Spiropoulos Y, Sakellariou GJ, Koutedakis Y. (2009). Effect of seasonal programming on fetal development and longevity: Links with environmental temperature. Am J Hum Biol. 21:214-216.

[12]. George L, Granath F, Johansson AL, Annerén G, Cnattingius S. (2006). Environmental tobacco smoke and risk of spontaneous abortion. Epidemiology. 17:500-505.

[13]. Griebel CP, Halvorsen J, Golemon TB, Day AA. (2005). Management of Spontaneous Abortion. Am Fam Physician. 72(7):1243-1250.

[14]. Ipas. (1991). Strategy for the Next Decade: Women's Health Initiatives. Ipas, Publication, Carrboro, NC, USA.

[15]. Lee SJ, Steer PJ, Filippi V. (2006). Seasonal patterns and preterm birth: a systematic review of the literature and an analysis in a London-based cohort. BJOG. 113:1280-1288.

[16]. McDonald AD. (1971). Seasonal Distribution of Abortions. Brit. J. prev. soc. Med. 25:222-224.

[17]. McGrath JJ, Barnett AG, Eyles DW. (2005). The association between birth weight, season of birth and latitude. Ann Hum Biol. 32:547-559.

[18]. Murray LJ, O’Reilly DP, Betts N, Patterson CC, Davey SG, Evans AE. (2000). Season and outdoor ambient temperature: effects on birth weight. Obstet Gynecol. 96:689-695.

[19]. National Population Commission (NPC) [Nigeria] and ICF International. 2014. Nigeria Demographic and Health Survey 2013. Abuja, Nigeria, and Rockville, Maryland, USA: NPC and ICF International.

[20]. Omo-Aghoja L, Aisien O, Akuse J, Bergstrom S, Okonofua F. (2010). Maternal mortality and emergency obstetric care in Benin City, south-south Nigeria. J Clin Med Res.2:55-60.

[21]. Oye-Adeniran BA, Umoh AV, Nnatu SN. (2002). Complications of unsafe abortion: A case study and the need for abortion law reform in Nigeria. Reprod Health Matters. 10(19):18-21.

[22]. Pope CA, Ezzati M, Dockery DW. (2009). Fine-Particulate Air Pollution and Life Expectancy in the United States. N Engl J Med. 360:376-386.

[23]. Postabortion Care Consortium Community Task Force, Essential Elements of Postabortion Care: an expanded and updated model, PAC in Action, 2002, No. 2, Special Supplement.

[24]. Sedgh G, Bankole A, Oye-Adeniran B, Adewole IF, Singh S, Hussain R. (2006). Unwanted pregnancy and associated factors among Nigerian women. Int Fam Plan Perspect 32(4):175-184.

[25]. Strand LB, Barnett AG, Tong S. (2011). The influence of season and ambient temperature on birth outcomes: a review of the epidemiological literature. Environ Res. 111:451-462.

[26]. Subramanjam V. (2007). Seasonal variation in the incidence of preeclampsia and eclampsia in tropical climatic conditions. BMC Womens Health. 7:18. Available from http://www.biomedcentral.com/1472-6874/7/18 [27]. Tustin K, Gross J, Hayne H. (2004). Maternal exposure to first-trimester sunshine is associated with increased birth weight in human infants. Dev Psychobiol.45:221-230.

[28]. Vineis P, Forastiere F, Hoek G, Lipsett M. (2004). Outdoor air pollution and lung cancer: recent epidemiologic evidence. Int J Cancer. 111:647-652.

[29]. Weinberg CR, Moledor E, Baird DD, Wilcox AJ. (1994). Is There a Seasonal Pattern in Risk of Early Pregnancy Loss? Epidemiology. 5(5): 484-489.

[30]. WHO (2012). Safe abortion: technical and policy guidance for health systems- $2^{\text {nd }}$ ed. World Health Organization, 20 Avenue Appia, 1211 Geneva 27, Switzerland.

[31]. Yackerson N, Piura B, Sheiner E. (2008). The influence of meteorological factors on the emergence of preterm delivery and preterm premature rupture of membrane. J Perinatol. 28:707-711. 